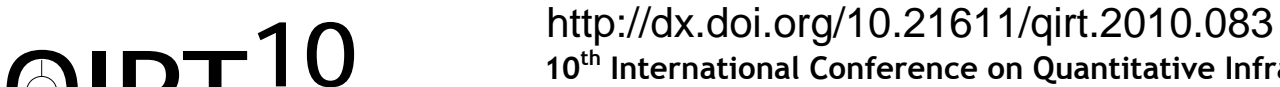 \\ $10^{\text {th }}$ International Conference on Quantitative InfraRed Thermography \\ July 27-30, 2010, Québec (Canada)
}

\section{Implementation of an infrared camera for road thermal mapping}

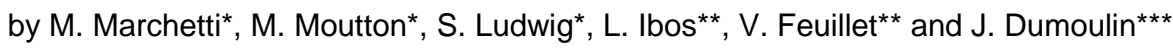 \\ * CETE de l'Est-ERA 31, 71 rue de la Grande Haie, 54510 TOMBLAINE Nancy, France, \\ Mario.Marchetti@developpement-durable.gouv.fr \\ ** CERTES-UPEC, Université Paris Est, 61 avenue du Général de Gaulle, 94010 Créteil Cedex, France, \\ ibos@univ-paris12.fr \\ *** LCPC, MACS, Route de Bouaye - BP 4129, 44341 Bouguenais Cedex, France, jean.dumoulin@Icpc.fr
}

\begin{abstract}
Thermal mapping has been implemented since the late eighties to establish the susceptibility of road networks to ice occurrence with measurements from a radiometer and some atmospheric parameters. They are usually done before dawn during wintertime when the road energy is being dissipated. The objective was to establish if an infrared camera could improve the determination of ice road susceptibility. Data analysis obtained from the radiometer and the infrared camera has shown great similarities. A comparison was made with promising perspectives. The measurement rate to analyse a given road network could be increased by a factor two.
\end{abstract}

\section{Introduction}

Thermal mapping has been implemented since the late eighties to measure road pavement temperature along with some other atmospheric parameters to establish the susceptibility of road network to ice occurrence [1-9]. Measurements are mainly done using a vehicle circulating on the road network in given road weather conditions (clear weather, cloudy, wet pavement, ...). These measurements are both used for the determination of a winter risk index based on the comparison of road surface temperature with dew point over the road network, and as an input for road weather forecast models based on energy balance. If the dew point temperature is below road surface temperature there is a risk of ice occurrence and therefore a loss of grip for circulating vehicles.

Road surface temperature is mainly obtained with an infrared radiometer providing measurements at a given spatial frequency whatever the speed of the vehicle was due to its insertion in traffic flow. The device is either installed outside or inside the vehicle. To avoid too much influence of the sun, and to see the thermal behavior of the pavement enhanced, thermal mapping is usually done before dawn during wintertime. That is when the energy accumulated by the road during daytime is mainly dissipated (by radiation, by conduction and by convection) and before the road structure starts a new cycle. The length of a road network ranges between a few hundreds of kilometres and up to several thousands kilometres when it comes to multiple lanes highways and an analysis in the two directions of a road.

This analysis is mainly done when a new road network is built, when some major pavement changes are made, or when modifications in the road surroundings took place that might affect the thermal heat balance. This helps road managers to install sensors to monitor road status on specific locations identified as dangerous, or simply to install specific road signs. A set of road events are collected by the operator (presence of bridges, urban areas, woods on road sides, pavement nature changes, ...) that might help in the analysis of road thermal response.

Measurements are run at speeds allowed on the road networks and ranging from a few $\mathrm{km} / \mathrm{h}$ and up to $110 \mathrm{~km} / \mathrm{h}$. They are anyhow time-consuming. Indeed, a whole road network can hardly be analysed at once, and has to be partitioned in stretches that could be done in the open time window to avoid temperature artefacts due to a rising sun.

The LRPC Nancy has been using a vehicle for thermal mapping since the early eighties. The vehicle is illustrated on figure 1. Although the whole device has great performances, such radiometer could only analyse one lane at a time. Furthermore, measurements being run before dawn, all road events are usually obtained making measurements during daytime. The road surface temperature obtained is then used to establish a rough cooling speed.

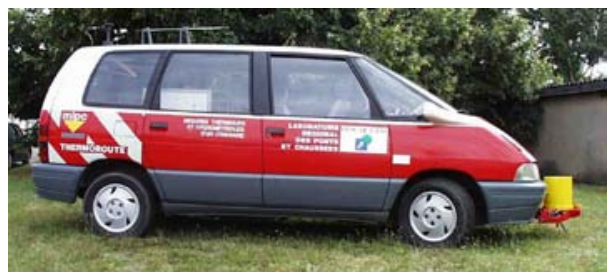

Fig. 1. : Vehicle for thermal mapping 
The objective of the work was to establish if the implementation of an infrared camera on a thermal mapping vehicle could improve the determination of road network susceptibility to ice occurrence by analysing several lanes in a same session. The analysis of road surface temperature obtained from the radiometer and the infrared camera are showing great similarities. Comparison was made on an area located between the wheel tracks. Promising perspectives appeared to increase by a factor two the measurement rate to analyse a given road network.

\section{Description of the experimental devices}

\subsection{Infrared radiometer PRT5 and atmospheric parameters}

The infrared radiometer is a PRT5 from Barnes pyrometer, with a $20^{\circ}$ field of view (FOV). It is mounted on the front bumper of a car, in a compartment which temperature is regulated around $18^{\circ} \mathrm{C}$. The compartment is located at about $40 \mathrm{~cm}$ above the road surface. The characteristics of the radiometer are given in table 1 . In our study, this radiometer was chosen has a reference for data analysis.

Table 1. Characteristics of PRT5 radiometer

\begin{tabular}{|l|l|}
\hline Detector type & bolometer detector \\
\hline Spectral bandwidth & $9.5-11.5 \mu \mathrm{m}$ \\
\hline Thermal range & $-40^{\circ} \mathrm{C}$ to $+70^{\circ} \mathrm{C}$ \\
\hline Sensitivity & $0.1^{\circ} \mathrm{C}$ below $0^{\circ} \mathrm{C}, 0.05^{\circ} \mathrm{C}$ above $0^{\circ} \mathrm{C}$ \\
\hline Accuracy & $\pm 0.5^{\circ} \mathrm{C}$ \\
\hline FOV & $20^{\circ}$ \\
\hline time response & $50 \mathrm{~ms}$ \\
\hline NET & 0.005 for a time response of $50 \mathrm{~ms}$ on a body at $25^{\circ} \mathrm{C}$ \\
\hline
\end{tabular}

During the measurements, usual atmospheric parameters such as air temperature, relative humidity and atmospheric pressure were monitored. Measurements were provided by a probe designed to be installed on moving vehicles, including aircrafts wings [10].

\subsection{Infrared camera FLIR® $S 65$ and thermal images}

A FLIR ${ }^{\circledR}$ S65 camera was used. This camera has an uncooled 320x240 FPA detector in band III. The camera is installed in a compartment attached to a window on the right side of the vehicle. The camera was plugged to a computer through an IEEE1394 firewire interface. The camera was turned at least 30 minutes before starting the measurements to make sure the whole electronic system has reached a thermal equilibrium. The characteristics of the camera are summarized in table 2.

Table 2. Characteristics of FLIR ${ }^{\circledR} S 65$ camera

\begin{tabular}{|l|l|}
\hline Detector type & Microbolometer detector uncooled IRFPA of 320x240 sensitive elements \\
\hline Spectral bandwidth & $7.5-13 \mu \mathrm{m}$ \\
\hline Thermal range used & $-40^{\circ} \mathrm{C}$ to $+120^{\circ} \mathrm{C}$ \\
\hline Sensitivity & $0.08^{\circ} \mathrm{C}$ \\
\hline Accuracy & $\pm 2 \%$ of the measurement \\
\hline FOV & $24^{\circ} \times 18^{\circ}(\mathrm{HxV})($ focal lens $35 \mathrm{~mm})$ \\
\hline IFOV & $1,3 \mathrm{mrad}$ \\
\hline lower image acquisition frequency & $1 \mathrm{~Hz}$ \\
\hline Video output & $\mathrm{Up} \mathrm{to} 50 \mathrm{~Hz}$ non interlaced \\
\hline
\end{tabular}

The camera FOV was such that each thermal image would embrace several elements of the scene, from the road pavement and up to the sky. In such configuration, the road is analyzed at a near grazing angle. A mirror was installed in the FOV of the camera, along with a surface painted with Nextel 811-21, which emissivity is considered as stable and equal to 0.97 [11]. The one of the mirror has been determined to 0.063 [12].

Due to the grazing angle, the measurement area for the infrared camera was located ahead of the radiometer one. There is so a distance offset between the temperature measurement obtained from the radiometer and the one from the 
infrared camera at the same time. This offset obviously depends on the area of the thermal image that would be investigated. The farther the area from the front of the vehicle, the greater the offset.

Infrared images obtained with the camera were analyzed with ThermaCam Researcher 2.9. Several regions of interest (ROIs) were defined on the mirror, on the Nextel coating and on the road pavement. This last one was such that no thermal interference due to circulating vehicles was included in the region of interest. A sketch of the instruments configuration along with an infrared image is given on figure 2 . In the chosen configuration for the data analysis, the distance offset was of $12 \mathrm{~m}$. This value is the distance between the point where the radiometer is making a measurement and the middle of the pavement ROI.
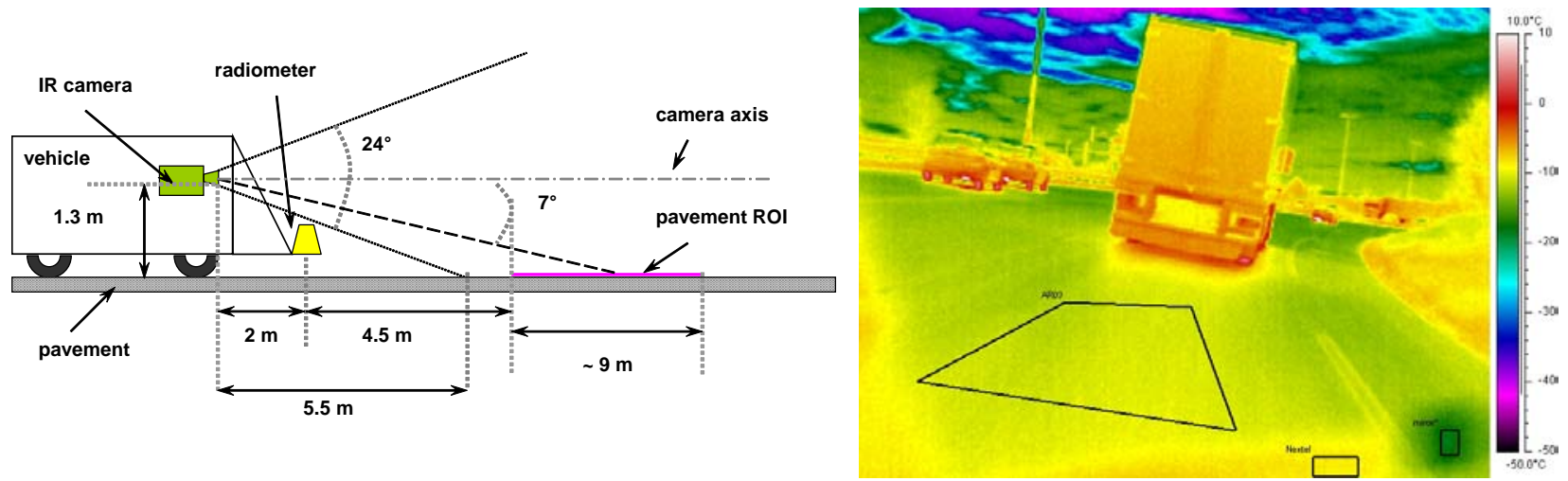

Fig. 2. : Sketch of instruments configuration (left) and thermal image from the vehicle with ROIs (right)

\subsection{Data acquisition}

Data acquisition for atmospheric parameters is performed every $3 \mathrm{~m}$ with a speed staying below $110 \mathrm{~km} / \mathrm{h}$ using a software interface developed under LabVIEW ${ }^{\circledR}$. Pavement emissivity was first supposed to be equal to one and to behave as a black body. A set of road events are collected by the operator (presence of bridges, urban areas, woods on road sides, ...) that might help in the analysis of road thermal response.

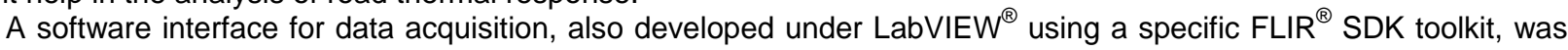
made. The code was written to proceed in a snapshot mode for thermal images acquisition. To cope with the camera time integration and limits with data transfer, thermal images were only acquired every $24 \mathrm{~m}$, at speeds staying below $70 \mathrm{~km} / \mathrm{h}$, and using FLIR native format. Despite the snapshot function, the microbolometer matrix and the whole electronic part of the infrared camera have an integration time of a few milliseconds. This time caused a slight blur in the thermal images when the vehicle is moving (trace behind object equivalent to two pixels at $70 \mathrm{~km} / \mathrm{h}$ in our measurement configuration). This aspect is compensated by a choice of ROIs for analysis which size exceeds the blur effect. All the atmospheric parameters measured by the different sensors such as air temperature and relative humidity were used as input parameters for the infrared camera when recording thermal images. The software interface is given on figure 3.

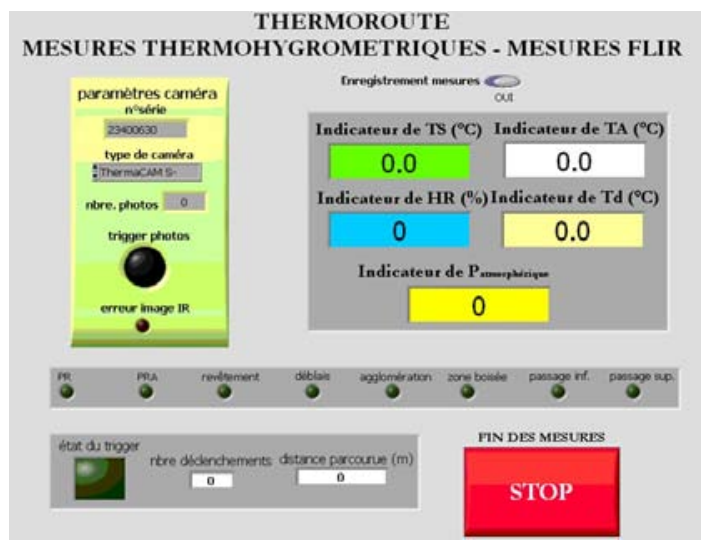

Fig. 3. : French software interface for data acquisition with atmospheric and infrared parameters 


\subsection{Road network pavement}

The road network chosen for the test was almost $30 \mathrm{~km}$ long and the measurement lasted nearly 30 minutes. It included several configurations, from single lane road to multiple lanes highway, passing above and below bridges, with and without trees on the roadside. Measurements were run without sun radiation to avoid artefacts, with a light cloud cover. The vehicle remained in the right lane when the driving was done on highway. A large distance with the vehicle right before was maintained to avoid its thermal signature.

In such a configuration, there were many variations in the materials that could be used for road pavement manufacturing. Furthermore, due to aging pavement and repairs, a wide variety of situations were met along these $30 \mathrm{~km}$. Therefore, a fixed and constant emissivity value could hardly be defined. The pavement emissivity could be considered as close to 1 for measurement close to the normal of the surface [11, 16]. Based on the literature [13-15], the emissivity decreases as the observation angle gets closer $90^{\circ}$ with respect to the normal of the analysed surface. Nevertheless, in this first approach, specularity of the pavement materials was neglected. So differences should be observed between radiometer and infrared camera data.

\section{Results and discussion}

Atmospheric and pavement measurements are given on the following figures. Pavement temperatures obtained with the infrared radiometer along with the ones from the camera are rough data before any treatment and environment corrections. An offset was observed between temperature measured, the camera temperatures being significantly colder. Nevertheless, the pavement temperature profiles evolution seems correlated. Furthermore, in both cases, major elements of the road environment such as bridges were properly detected by both instruments. Before any measurement correction, thermal amplitude was larger with the camera $\left(11^{\circ} \mathrm{C}\right)$ than it was with the radiometer $\left(6^{\circ} \mathrm{C}\right)($ see Fig. 4$)$.

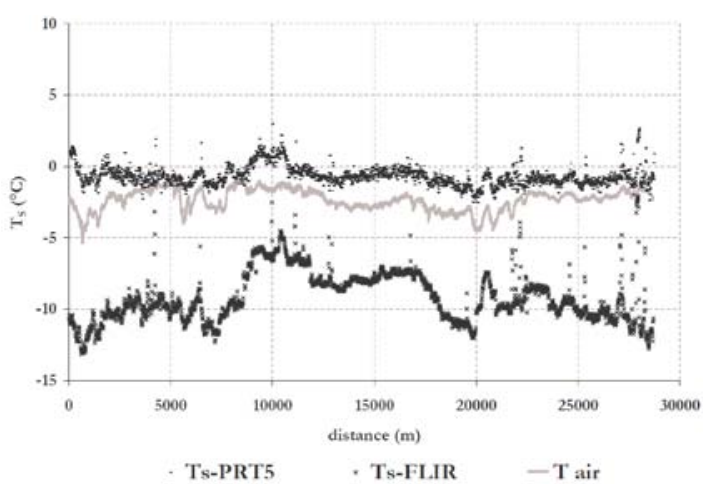

Fig. 4. : Surface temperature measured with the radiometer and the infrared camera, and air temperature as a function of distance before any correction

The radiance balance of the whole system could be written as Eq. (1).

$$
L_{\text {measured }}=\tau_{\text {atmosphere }} \cdot \varepsilon_{\text {pavement }} \cdot L_{\text {pavement }}+\tau_{\text {atmosphere }} \cdot\left(1-\varepsilon_{\text {pavement }}\right) \cdot L_{\text {environment }}+\left(1-\tau_{\text {atmosphere }}\right) \cdot L_{\text {atmosphere }}
$$

In the chosen configuration the distance between road and infrared camera is around fifteen meters for the most distant point were a measurement is done. The meteorological situation was such that neither cloud, nor fog were present during the measurements. The atmospheric transmission coefficient $\tau_{\text {atmosphere }}$ was equal to one. The part due to the atmosphere could therefore be neglected.

The infrared camera measurements were done considering bodies in its field of view emitting infrared radiation as black bodies. Eq. (1) then becomes Eq. (2) without considering the specularity. The radiance from the environment was obtained thanks to the mirror installed in the field of view of the infrared camera. As described in the previous paragraphs, measurements were done with the camera having a grazing angle with respect to pavement surface. In such a situation, the emissivity is below the conventional 0.95 to 0.98 value for non-metallic materials in general and asphalt concrete in particular $[11,16]$. An emissivity value of 0.77 was selected, consistent with the literature [15]. Such a choice was made to fulfill the grazing angle situation. It also allowed getting temperature measurements from the infrared camera matching the values from the PRT5 radiometer chosen as a reference. Thanks to Eq. (2), pavement temperature with an environment correction could be obtained. 


$$
T_{\text {measured }}^{4}=\varepsilon_{\text {pavement }} \cdot T_{\text {pavement }}^{4}+\left(1-\varepsilon_{\text {pavement }}\right) \cdot T_{\text {environment }}^{4}
$$

Once the radiative corrections completed, a second one was performed to take into account the distance offset between systems, as illustrated on figure 2 where the measurement with the infrared camera is ahead of the one of the radiometer. Results presented in figure 5 show a good concordance between temperatures issued from both instruments once included these corrections. A partition of the whole itinerary was set to ease its legibility.

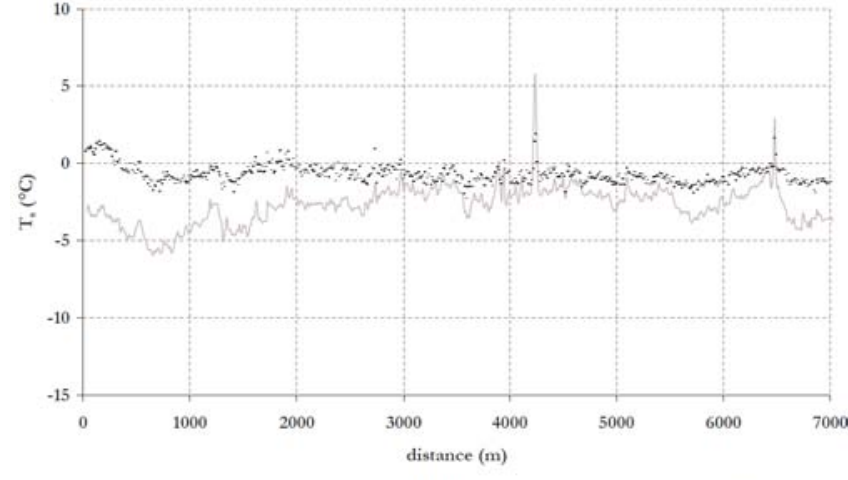

Ts PRT5 ( $\left.{ }^{\circ} \mathrm{C}\right)$

(a) 0 to $7000 \mathrm{~m}$

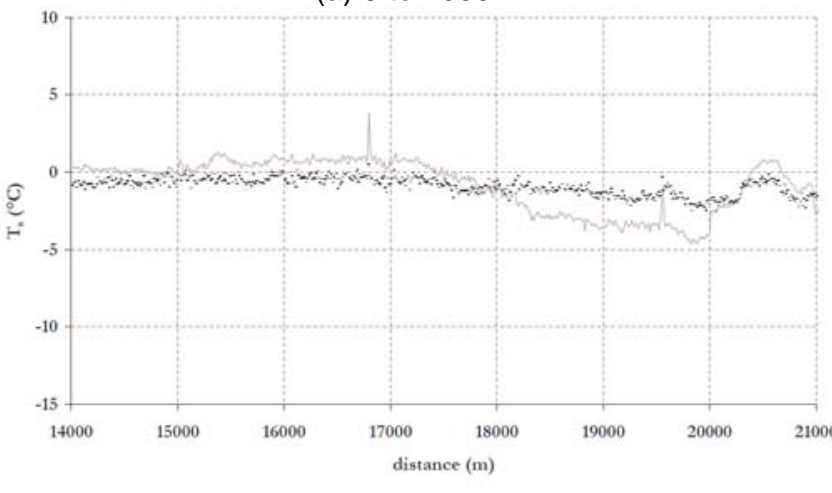

- Ts PRT5 $\left({ }^{\circ} \mathrm{C}\right) \quad$ Ts FLIR corrected (emissivity, distance offset)

(c) 14000 to $21000 \mathrm{~m}$

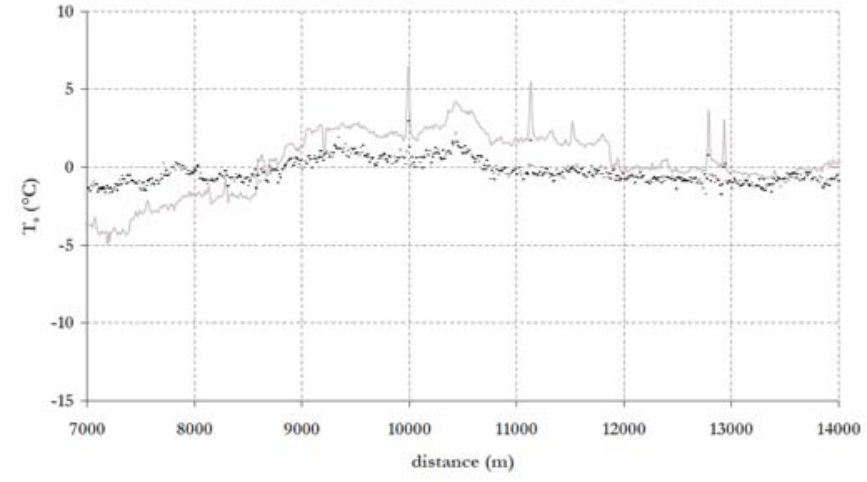

Ts PRT5 $\left({ }^{\circ} \mathrm{C}\right) \quad$ Ts FLIR corrected (emissivity, distance offset)

(b) 7000 to $14000 \mathrm{~m}$

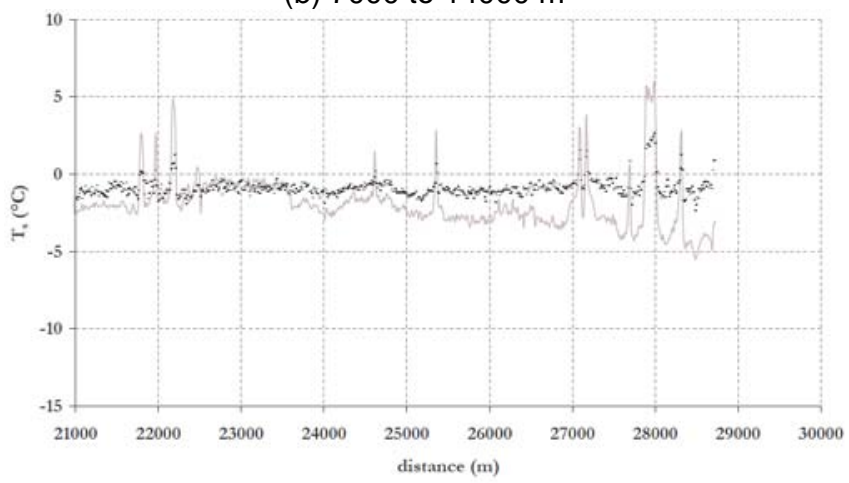

Ts PRT5 $\left({ }^{\circ} \mathrm{C}\right) \quad$ Ts FLIR corrected (emissivity, distance offset)

(d) 21000 to $30000 \mathrm{~m}$

Fig. 5. : Temperature measurements as a function of distance after emissivity and distance offset corrections

With this set of corrections, the distribution of pavement temperatures and of pavement temperatures difference $\Delta T_{s}$ between the two infrared instruments were established and results shown in figure 6 . The pavement temperatures difference distribution is centered above $1^{\circ} \mathrm{C}$, with a standard deviation of $1.8^{\circ} \mathrm{C}$. Based on the values given in tables 1 and 2 , data was clearly within the sensitivity and accuracy of the instruments.
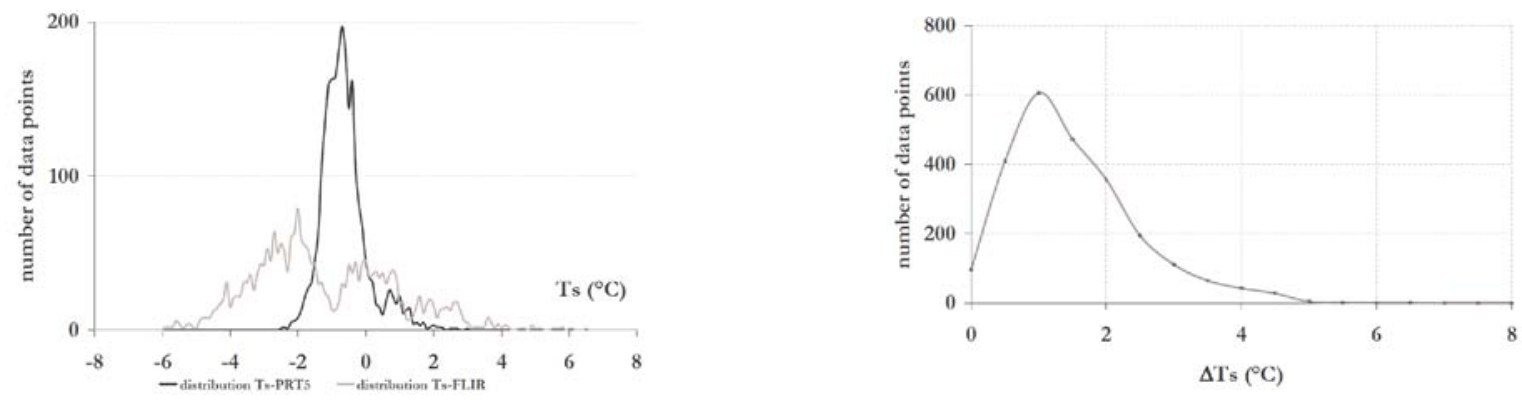

Fig. 6. : Pavement temperature distributions and difference $\Delta T_{s}=T_{s}(P R T 5)-T_{s}(F L I R)$ 
Many possibilities exist in the calculation of the winter risk WR of an itinerary. In France, average measured parameters (air temperature, relative humidity, pavement temperature, dew point) are commonly used to analyse icing risk of an itinerary. WR is then defined according to Eq. 3:

$$
\begin{aligned}
& \mathrm{WR}=2 . \mathrm{WR}\left(\mathrm{T}_{\mathrm{s}}\right)+\mathrm{WR}\left(\mathrm{T}_{\mathrm{d}}\right), \\
& \text { with } \mathrm{WR}\left(\mathrm{T}_{\mathrm{s}}\right)=0 \text { if } 0^{\circ} \mathrm{C} \leq \mathrm{T}_{\mathrm{s} \text {,average }}-\mathrm{T}_{\mathrm{s}}<0.5^{\circ} \mathrm{C} ; 1 \text { if } 0.5^{\circ} \mathrm{C} \leq \mathrm{T}_{\mathrm{s} \text {,average }}-\mathrm{T}_{\mathrm{s}}<1^{\circ} \mathrm{C} ; \ldots \\
& \text { and } \mathrm{WR}\left(\mathrm{T}_{\mathrm{d}}\right)=0 \text { if } 0^{\circ} \mathrm{C} \leq \mathrm{T}_{\mathrm{d} \text {,average }}-\mathrm{T}_{\mathrm{d}}<0.5^{\circ} \mathrm{C} ; 1 \text { if } 0.5^{\circ} \mathrm{C} \leq \mathrm{T}_{\mathrm{d} \text {,average }}-\mathrm{T}_{\mathrm{d}}<1^{\circ} \mathrm{C} ; \ldots
\end{aligned}
$$

The winter risk was then calculated using pavement temperatures measurements of the PRT5 radiometer as usually done, and with data from the infrared camera, once the emissivity and distance offset correction done. They are illustrated in figure 7, with a partition of the whole itinerary. The global WR shape was respected, though values were clearly different from one instrument to the next. Such difference has to be moderated because of the method chosen for WR calculation. Furthermore, as illustrated on figure 6, the pavement temperatures distributions from both instruments are greatly different though gaussian in both cases. WR is greatly sensitive to the average obtained. In the case of the PRT5 radiometer, the average temperature is slightly above $-0.7^{\circ} \mathrm{C}$, while it is near $-1.3^{\circ} \mathrm{C}$ in the case of the FLIR camera. Average value for due point is the same in both cases. Therefore, a difference will appear in the WR evaluation.

The measurement with the infrared camera was based on many elements from the road environment, enhancing the thermal amplitude of the ROI. The one used for pavement temperature had a given spatial extent. And due to the grazing angle, pavement points farther from the vehicle appeared colder than the ones near the vehicle. A temperature difference up to $2^{\circ} \mathrm{C}$ was recorded along thermal images based on figure 2 pavement ROI. This also contributed to increase the thermal amplitude within the ROI. This could be corrected considering an emissivity distribution within the instead of attributing a constant emissivity. Indeed, emissivity drops quickly when it comes to such low observation angles (below $10^{\circ}$ ). So, once the average pavement temperature was calculated for $W R$, variations around it were enhanced with the infrared camera and this clearly affected the WR which appeared greater that the one was obtained with the radiometer.

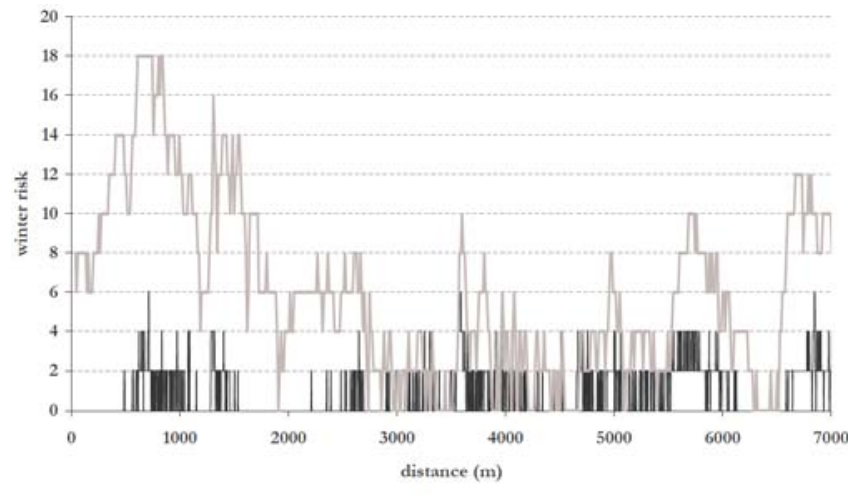

-WR_PRT5 - WR_FLIR

(a) 0 to $7000 \mathrm{~m}$

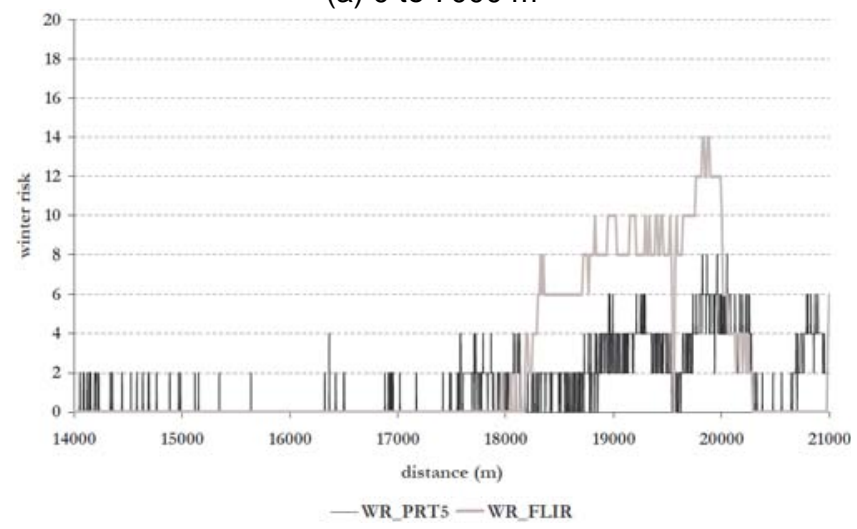

(c) 14000 to $21000 \mathrm{~m}$

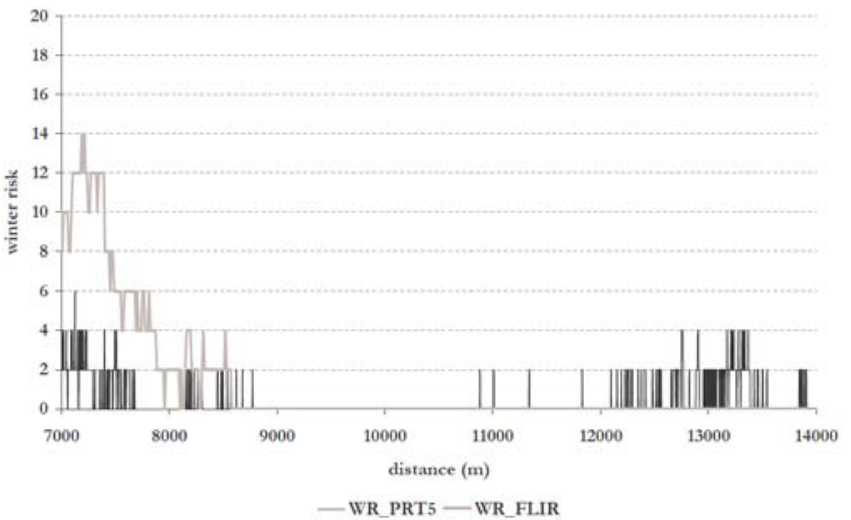

(b) 7000 to $14000 \mathrm{~m}$

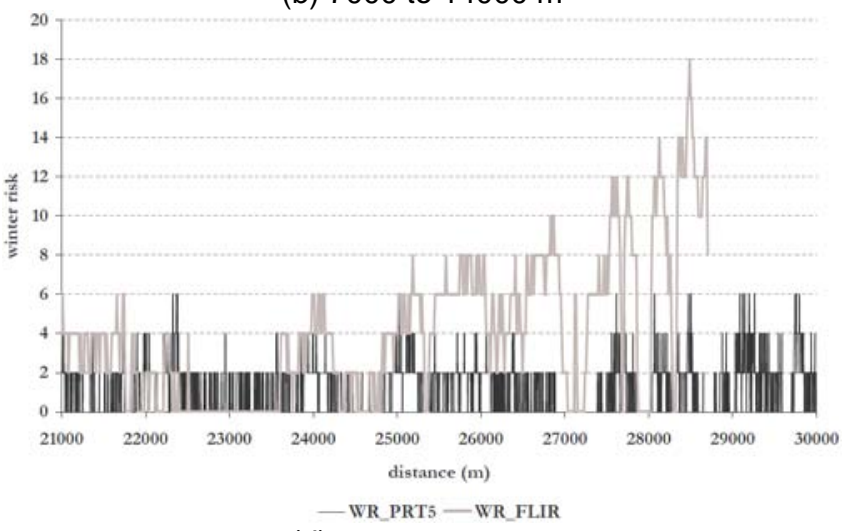

(d) 21000 to 30000

Fig. 7. : Winter risks obtained with infrared radiometer and the camera 


\section{Conclusion}

The objective of this work was to establish the possibility to implement an infrared camera (FLIR ${ }^{\circledR}$ S65) on a thermal mapping vehicle to have at a same time multiple-lane analysis in one shot and for and extended road surface. Once completed, such measurement configuration was compared to current measurement system in use (PRT 5 radiometer) to compute the index of susceptibility of road network to ice occurrence. To do so, a $30 \mathrm{~km}$-long itinerary was chosen, including different road configurations (highways, urban area, bridges, trees, ...). The infrared camera was installed on board of a pavement monitoring vehicle. Simplified radiometric corrections were done to take into account the inclination of infrared camera with respect to road surface. Furthermore, road data spatial offset between the two measurement systems was corrected. A LabVIEW ${ }^{\circledR}$ interface was developed for data acquisition, including atmospheric parameters and infrared images.

Road surface temperatures analysis obtained from the radiometer and the infrared camera have shown similarities. A comparison was made on an area located between the wheel tracks. Once radiometric and distance offset correction performed, there was a good agreement between the surface temperature measurements. Data from the infrared camera indicated greater thermal amplitude. This could be explained by the grazing angle that should induce an emissivity correction with a distribution over the region of interest, and not only a single value as performed in a first approximation. The winter risk calculation was conducted according to a very traditional and simplistic way. Because of the greater thermal amplitude obtained with the camera and the differences between pavement temperature averages from both instruments, a larger winter risk was deduced along the network with respect to the one obtained with the radiometer.

As a conclusion, the feasibility of performing thermal mapping with an infrared camera was established. This would improve the performance by measuring pavement temperatures in several road lanes at the same time. The position of the camera has to be optimized according to its field of view. Although the thermal images acquisition frequency is comfortable, a reduction from 24 to $12 \mathrm{~m}$ would ease data analysis. This could be performed acquiring data only in the region of interest instead of the whole image, reducing its volume. A compromise has to be found to get information about road surroundings, and to avoid radiation from passing vehicles.

\section{REFERENCES}

[1] Thornes, J.E. The prediction of ice formation on motorways in Britain. Unpublished PhD Thesis, Department of Geography, University of London, UK., 1984.

[2] Thornes, J. E. Thermal mapping and road-weather information systems for highway engineers. Highway Meteorology, A. H. Perry and L. J. Symons, Eds., E and FN Spon, pp. 39-67, 1991.

[3] Belk D.G., "Thermal mapping for a highway gritting network", Ph D thesis, University of Sheffield, ISBN z0940068, 1993.

[4] Shao J., Lister P.J., Pearson H.B., "Thermal Mapping: reliability and repetability", Meteorol. Appl. 3, pp. 325-330, 1996.

[5] Shao J., Swanson J.C., Patterson R., Lister P.J., McDonald A.N., "Variation of winter road surface temperature due to topography and application of Thermal Mapping", Meteorol. Appl. 4, 131-137 (1997).

[6] Gustavsson T., Thermal mapping - a technique for road climatological studies. Meteorological Applications, 6, pp. 385-394, 1999.

[7] Chapman, L., Thornes, J.E. \& Bradley, A.V. Modelling of road surface temperature from a geographical parameter database. Part 2: Numerical. Meteorological Applications 8, pp. 421-436, 2001.

[8] Chapman, L. \& Thornes, J.E. A geomatics based road surface temperature prediction model. Science of the Total Environment 360: 68-80, 2006.

[9] Chapman L., Thornes J.E., Small-scale road surface temperature and condition variations across a road profile. Proceedings of the $14^{\text {th }}$ SIRWEC conference, WIRELESSCOM, s. r. o. (Prague, Czech Republic), ISBN 978-8087205-01-3, 2008.

[10] http://www.forumgraphic.eu/prod/index.php/Mesure/sonde-basse-couche.html

[11] Ibos L., Marchetti M., Boudenne A., Datcu S., Candau Y., Livet J., Infrared emissivity measurement device: principle and applications, Meas. Sci. Technol., 17, pp. 2950-2956, 2006.

[12] Dactu S., Ibos L., Candau Y., Mattei S., Improvement of building wall surface temperature measurements by infrared thermography, Infrared Physics \& Technology, 46, pp. 451-467, 2005.

[13] Maldague X.P.V., Theory and Practice of Infrared Technology for Nondestructive Testing, John Wiley \& sons, Inc., 684 p, 2001.

[14] Gaussorgues G., La thermographie infrarouge. Techniques et Documentation (France), 386 p., 1981.

[15] Handbook of Military Infrared Technology, Office of Naval Research Department of the Navy (Washington D.C., USA), 906 p,1965.

[16] Marchetti M., Ibos L., Valérie Muzet, Pitre R., Boudenne A., Datcu S., Candau Y., Livet J., Emissivity Measurements of Road Materials, QIRT Journal, Volume 1, Issue 1, pp. I.2.1-I.2.7, 2004. 